\title{
CONTRATOS E CONTRATADORES DO ATLÂNTICO SUL NA SEGUNDA METADE DO SETECENTOS
}

\author{
FÁBIO PESAVENTO \\ Escola Superior de Propaganda e Marketing \\ CARLOS GABRIEL GUIMARÃES \\ Universidade Federal Fluminense
}

\section{RESUMO}

O presente trabalho tem como objetivo analisar, introdutoriamente, os principais contratos e os contratadores de algumas das principais capitanias do Brasil colonial na segunda metade do XVIII: Rio de Janeiro e Rio Grande de São Pedro. Visto o limite da Coroa na implementação e controle de sua arrecadação, além da constante necessidade do aumento das rendas, a arrematação dos contratos era uma opção frente à constante falta de recursos da Coroa. O sistema de contratos reais obteve êxito por diversos motivos entre os quais a participação de um poderoso grupo mercantil da praça do Rio de Janeiro, formado pelos principais homens de negócio, que constituiu uma sociedade que arrematou os principais contratos, e cujo volume de recursos envolvido demonstra que esses negociantes, ao contrário do que afirmou o Marquês do Lavradio, não eram meros consignatórios, nem estavam num segundo plano frente aos negociantes de outras praças mercantis.

PALAVRAS-CHAVE: Brasil colônia; comércio colonial; grupos mercantis coloniais.

\begin{abstract}
The purpose of this article is an introductory analysis of the main contracts and contractors in the territory under two important captaincies in colonial Brazil in the second half of the 18th century, namely Rio de Janeiro and Rio Grande de São Pedro. Considering the Crown limits for tax-collection increase, the purchase of contracts was seen as an alternative. The royal contracts succeeded for several reasons, among which the participation of a powerful commercial group in Rio de Janeiro, who bought the most important contracts. Such a group and the amount of financial resources clearly show that the merchants in Rio, unlike Marquis de Lavradio's assertion, were more than mere co-signatories and were not on a second level compared with merchants from other markets.
\end{abstract}

KEYWORDS: Colonial Brazil; colonial trade; colonial merchants. 
Com a necessidade do aumento das rendas, a arrematação dos contratos era uma opção frente à constante falta de recursos da Coroa. Entretanto, era necessário o sucesso desse sistema, o que foi conseguido com a participação de um poderoso grupo mercantil da Praça do Rio de Janeiro. Formado pelos principais homens de negócios da praça fluminense e riograndense, esses constituíram grandes sociedades com a finalidade de arrematar os principais contratos do Atlântico Sul. Tal sociedade e o volume de recursos para a arrematação dos contratos demonstram que os negociantes atuantes no Rio de Janeiro e Rio Grande de São Pedro, ao contrário do que afirmou o Marquês do Lavradio, não eram meros consignatórios, muito menos pertenciam a um segundo plano dos negócios coloniais.

De origem no século XVI, o sistema de contratos das rendas e direitos reais constituiu-se numa das principais formas de arrecadação para as receitas do Estado Imperial Português dos tempos modernos. Estabelecido em acordos temporários entre o Rei, como representante da Coroa, e particulares, ordinariamente negociantes de grosso trato, tal sistema tinha prazos e quantias fixados, com direitos e deveres preestabelecidos a serem cumpridos pelas partes. O presente trabalho tem como objetivo analisar, introdutoriamente, os principais contratos e os contratadores atuantes no Atlântico sul. Nesse caso, a análise vai se restringir às Capitanias do Rio de Janeiro e de Rio Grande de São Pedro durante a segunda metade do século XVIII.

Tornando-se sede do Vice-Reino do Estado do Brasil, e com o crescimento da atividade comercial e portuária desde o início do século XVIII, a cidade e a capitania do Rio de Janeiro cresceram econômica e politicamente, fixando-se como áreas estratégicas para o Estado Imperial Português.

Após a ascensão de Sebastião José de Carvalho e Melo (Marquês de Pombal, 1750-1777), a política de recuperação das rendas reais tomou corpo, no Brasil colonial, com a nomeação de Marquês de Lavradio para o governo da Capitania do Rio de Janeiro, em 1768. A nomeação do ex-governador da Bahia, um dos prediletos e de confiança do Marques de Pombal para o Rio de Janeiro, estava relacionada à principal política pombalina do período: "aumento dos rendimentos e na boa arrecadação deles".

Este artigo foi dividido em três partes. A primeira trata dos contratos na historiografia e é seguida por um breve contexto da economia brasileira durante a segunda metade do setecentos. Por fim, é apresentada a trajetória dos principais contratadores atuantes no Atlântico Sul.

\section{Os contratadores na historiografia}

Tal sistema (arrecadação dos tributos por contratos) constituiu uma das mais maléficas práticas do governo colonial. Justificava-se aliás, porque estava nos métodos fiscais de todas as nações contemporâneas, e tinha atrás de si uma tradição de séculos desde o Império Romano. Mas esta respeitável vetustez do sistema não era consolo para a população colonial, que sofreu muito dele. Os ávidos contratadores, sem outra 
consideração que o negócio em vista, não tinham contemplação nem tolerância. ${ }^{1}$

Nesta parte do trabalho pretende-se realizar uma brevíssima revisão da historiografia sobre contratos e contratadores. A historiografia sobre os contratadores, até recentemente, foi influenciada pela leitura de Caio Prado Júnior. Consoante a citação acima, Prado Júnior destacava que a administração fiscal, assim como a própria administração colonial, era desorganizada, "um amontoado que nos parece inteiramente desconexo, determinações particulares e casuísticas, de regras que se acrescentam umas às outras sem obedecerem a plano algum de conjunto", 2 e que os contratadores, os "dizimeiros", estavam somente interessados nos seus negócios particulares e em explorar a população colonial.

Preocupado com a estrutura econômica e social da colônia portuguesa na América, baseada na plantation escravista, Prado Júnior não destacou a importância dos contratadores, enquanto agentes reais do fisco, nem priorizou uma atividade econômica ligada a eles, o comércio (principalmente o comércio interno colonial) ${ }^{3}$.

Constituindo-se numa prática política e econômica de um Estado, seja de Antigo Regime, ${ }^{4}$ seja de uma Época Mercantilista, ${ }^{5}$ a contratação ou ação de assentar mediante estabelecimento de contrato, segundo Miriam Ellis,

refere-se à exploração ou ao comércio ou trato de mercadorias (respectivamente a exploração do óleo de baleia e o comércio do sal, por exemplo), bem como à arrematação, mediante contrato, do privilégio para a cobrança de tributos e rendimentos reais. Em ambos os casos, o Estado recebia antecipadamente determinados rendimentos destinados a enfrentar as muitas vezes prementes necessidades do Tesouro. ${ }^{6}$

Portanto, os contratadores são arrendatários que arrematavam monopólios e a cobrança de direitos (dízimos) e de tributos (registros de passagens). Tal prática, que remonta, no caso de Portugal, aos primeiros tempos da monarquia, no século XVII e, principalmente, no XVIII, estava associada aos negociantes de grosso (homens de negócios). Virgínia Rau, na

\footnotetext{
${ }^{1}$ PRADO JÚNIOR, Caio. Formação do Brasil Contemporâneo: colônia. 20a ed. São Paulo: Brasiliense, 1980, p.319-320.

2 PRADO JÚNIOR, op. cit., p. 300

3 Embora trate do comércio interno, Caio Prado Jr o relaciona como uma atividade complementar ao principal, o comércio externo. PRADO JÚNIOR, op. cit., p. 228-237.

4 GOUVÊA, Maria de Fátima; FRAGOSO, João; BICALHO, Maria Fernanda (org.). O Antigo Regime nos trópicos: a dinâmica imperial portuguesa (séculos XVI-XVIII). Rio de Janeiro, Civilização Brasileira, 2001.

5 BELLOTTO, Heloísa Liberalli. O Estado Português no Brasil: Sistema Administrativo e Fiscal. In: SILVA, Maria Beatriz (coord.). Nova História da Expansão Portuguesa. O Império Luso-Brasileiro (1750-1822). Lisboa: Estampa, 1986.

${ }^{6}$ ELLIS, Myriam. O Monopólio do Sal no Estado do Brasil. São Paulo: FFCL, 1955, p. 99.
} 
década de 1950, analisando a atuação dos "negociantes de grosso trato" no comércio colonial português, especialmente nos contratos do sal, tabaco e escravos, enfatizou a necessidade de se estudar esse ator social. Para a historiadora portuguesa,

o estudo da sociedade luso-brasileira do século XVIII ficará incompleto se nele não inserirmos a contextura da vida profissional e particular dos mercadores de grosso trato que, no Brasil e em Portugal, arrematavam contratos, emprestavam a juros, negociavam em sal, tabaco, escravos, ouro, diamantes, e toda a espécie de mercadorias, interferindo assim na vida econômico-social da metrópole e dos seus domínios ultramarinos. ${ }^{7}$

Conhecidos como os comerciantes que negociam a grosso, os negociantes atacadistas ou negociantes capitalistas, nas palavras de Max Weber e de Fernand Braudel, ${ }^{8}$ diferenciavam-se dos demais comerciantes, como os retalhistas ou lojistas, pois

compreende a ocupação de um membro que remete para os países estrangeiros as produções da sua pátria, ou seja, com o fim de trocá-las por outras necessárias, ou por dinheiro este comércio feito por terra, ou por mar, na Europa, ou com outras partes do mundo, tem distinto nome de comércio em grosso, e os que se ocupam nele são chamados de homens de negócios. ${ }^{9}$ (grifo nosso)

Tendo como principal atividade o comércio de longa distância, os homens de negócios tiveram uma grande mobilidade na sociedade imperial portuguesa setecentista. Seja em Lisboa, seja em outras regiões de diferentes centros mercantis do Império, como na Bahia, Rio de Janeiro e Minas Gerais, essa mobilidade, fruto do seu prestígio econômico e político, permitiu que muitos fossem habilitados na Ordem de Cristo, a principal Ordem Militar do Império Português, e recebessem mercês e sesmarias nas colônias. No início da década de 1980, retornando ao tema dos contratadores e negociantes, ${ }^{10}$ Myrian

\footnotetext{
${ }^{7}$ RAU, Virgínia. Um mercador luso-brasileiro do século XVIII. In: GARCIA, José Manuel (Org.) Estudos sobre História Econômica e Social do Antigo Regime. Lisboa: Ed. Presença, 1984, p. 19 (grifo nosso).

8 WEBER, Max (1968). História Geral da Economia. São Paulo, Mestre Jou, 1968, cap. 4; BRAUDEL, Fernand. Civilização Material, Economia e Capitalismo séculos XV-XVIII, tomo II, $O$ Jogo das Trocas. Lisboa: Teorema, 1991, p. 329-382.

9 SALES, Alberto Jaqueri de. Diccionario Universal de Commercio, tradução e adaptação manuscrita do Dictionnaire Universel de Commerce, de Jacques Savary de Brulons, 3 vols., 1813. O dicionário francês foi editado em 1723.

10 A respeito dos contratos e contratadores do sal e da pesca da baleia na colônia cf. ELLIS, op.cit.; e da mesma autora, A Baleia no Brasil Colonial. São Paulo: Melhoramentos, 1969.
} 
Ellis ressaltou a necessidade de aprofundar os estudos desses atores sociais na sociedade colonial, pois,

mencionar contratos e contratadores é pressupor o monopólio, em geral e, em particular, bem como a presença dos comerciantes no panorama econômico e social luso-brasileiro, desde os primórdios (...). Monopólios, arrendamentos e contratos, antigas e tradicionais práticas desenvolvidas em Portugal também o foram no Brasil. ${ }^{11}$

Como exemplo de estudo de caso de um contratador e de sua atuação no comércio e na sociedade colonial, Miriam Ellis destacou a atuação de Francisco Pinheiro e a necessidade de aprofundar uma pesquisa sobre ele. ${ }^{12}$

Na década de 1990, Nuno Luis Madureira e Jorge Miguel Viana Pedreira avançaram os estudos sobre os contratadores. O primeiro autor, ao relacionar a relação entre o Estado Português e os negociantes, através da inserção desses na Real Junta de Comércio, destacou a relação entre a arrematação e os privilégios dos negociantes/contratadores no mercado colonial português ${ }^{13}$. Jorge Pedreira, a seu turno, ao estudar os principais negociantes portugueses da Praça de Lisboa (de Pombal ao Vintismo), chamou atenção para o fato de que ser contratador significava para o negociante estar no topo da hierarquia mercantil. Ser contratador, um agente da Coroa, consistia numa diferenciação no interior do grupo mercantil. ${ }^{14}$

O trabalho de Jorge Pedreira influenciou estudos monográficos (dissertações) no Brasil. Embora pesquisas importantes envolvendo o comércio interno e os registros destacassem os contratadores, estes não eram o objeto dessas propostas. ${ }^{15}$ A respeito dos contratadores, destacamos os trabalhos de Luiz Antônio Araújo e de Fernando Gaudereto Lamas e, mais recentemente, o de Sofia L. V. Antezana. Tais estudos, tendo como espaço político, social e

${ }^{11}$ ELLIS. O monopólio..., p. 121.

12 A respeito da historiografia sobre Francisco, cf. LEVY, LEVY, Maria Barbara. (1998) História Financeira do Brasil Colonial. Rio de Janeiro, IBMEC, 1998; . DONOVAN, William Michael. Commercial Enterprise and Luso-Brazilian Society during the Brazilian Gold Rush: the Mercantile House of Francisco Pinheiro and the Lisbon to Brazil Trade, 1695-1750. Maryland: The Johns Hopkins University, 1990; FURTADO, Júnia Ferreira. Homens de Negócio. A Interiorização da Metrópole e do Comércio nas Minas Setencentistas. São Paulo: HUCITEC, 1999; GUIMARÃES, Carlos Gabriel. O Fidalgo-Mercador Francisco Pinheiro e o "Negócio da Carne Humana", 17071715. In SOARES, Mariza de Carvalho (org.). Rotas Atlânticas da diáspora africana: da Baía do Benim ao Rio de Janeiro. Niterói, EDUFF, 2007.

13 MADUREIRA, Nuno Luís. Mercado e Privilégios: a indústria portuguesa entre 1750-1834. Lisboa: Estampa, 1997.

14 PEDREIRA, Jorge. Os homens de negócio da Praça de Lisboa de Pombal ao Vintismo (17551822): diferenciação, reprodução e identificação de um grupo social. Tese de doutoramento. Lisboa: UNL, 1995.

15 CHAVES, Claudia Maria das Graças. Perfeitos negociantes: mercadores das Minas Setecentistas. São Paulo: Annablume, 1999; SAMPAIO, Antônio Carlos Jucá de. Na Encruzilhada do Império: hierarquias sociais e conjunturas econômicas no Rio de Janeiro (c.1650 -c.1750). Rio de Janeiro: Arquivo Nacional, 2003; CARRARA, Ângelo Alves. Minas e currais. produção rural e mercado interno de Minas Gerais, 1674-1807. Juiz de Fora: Editora da UFJF, 2006. 
econômico a capitania das Minas Gerais setecentista, destacam o poder dos contratadores, seja na Capitania, seja no interior do Império Português. Por meio de redes clientelares, e de estratégias envolvendo compadrios, casamentos e outros, esses agentes da Coroa constituíram-se não só num grupo mercantil mas, em algumas capitanias, no próprio grupo dominante, como no Rio de Janeiro, São Paulo e Minas Gerais. A aliança dos Governadores com esse grupo mercantil/contratador era fundamental para a renda da Capitania, como também da própria Fazenda Real.

Consoante as instruções para o Governador e capitão-General de Vila Rica a respeito da arrecadação,

o principal objeto que deve ter presente quem teve a honra de ser empregado de qualquer governo ultramarino é a boa administração das rendas. Em duas partes se divide a boa administração da fazenda, quanto à direção de qualquer governo ultramarino é a boa administração das Rendas Reais de que tanto depende a segurança pública por serem as conquistas a fonte de que emanam as riquezas que fazem respeitado e opulento o Estado. $\mathrm{O}$ aumento das Rendas Reais depende principalmente da Agricultura, da Indústria, da fácil circulação do comércio e da boa arrecadação da Real Fazenda. São o Comércio e a Agricultura as duas bases nas quais, mais do que em outras, se costumam sustentar os três rendimentos mais consideráveis (...). ${ }^{16}$

Portanto, a preocupação da Coroa com a arrecadação dos tributos e direitos submetidos a contrato é de fundamental importância para a análise da economia da Capitania do Rio de Janeiro. Esse assunto será tratado a seguir.

\section{Da serra para o pampa: o contexto econômico do Rio de Janeiro e do Rio Grande de São Pedro no século XVIII}

$\mathrm{Na}$ primeira parte deste artigo foram debatidos os contratos na historiografia. Agora, nesta segunda parte, pretende-se analisar a economia do Rio de Janeiro e do Rio Grande de São Pedro na segunda metade do setecentos e, além disso, realizar um breve panorama sobre o contexto econômico e político desse importante período da economia luso-brasileira.

Dom José I ascende ao Reino português em $1750{ }^{17} \mathrm{e}$, junto com ele, assumia a pasta dos negócios uma das personagens mais importantes da história luso-brasileira: Sebastião José de Carvalho e Melo, o Marquês de

${ }^{16}$ Apud BellotTo, op. cit. , p. 283 (grifo nosso).

17 Ver PEDREIRA, op. cit. LAINS, Pedro; SILVA, Álvaro Ferreira da (Orgs.). História econômica de Portugal: 1700-2000. Vol. 1. Lisboa: Imprensa de Ciências Sociais, 2005; HESPANHA, António Manuel (coord.). História de Portugal: o Antigo Regime (1620-1807). Lisboa: Estampa, 1998. 
Pombal. ${ }^{18}$ Ele pertencia a uma família com pouco prestígio junto à Corte lusitana e seu acesso a essa seara só teve início após casar-se com dona Thereza de Noronha e Bourbon Mendonça e Almada, em 1723 (antes disso, magistrava sem maiores alardes).

O matrimônio com dona Thereza (viúva de posses e sobrinha do Conde dos Arcos) permitiu-Ihe o acesso e uma maior exposição na vida pública. Depois de uma passagem importante pela Real Academia de História, foi designado para ser diplomata em Londres, no ano de 1738, onde permaneceu até 1743. Nesse período, conheceu a importância e pujança da economia manufatureira inglesa. Também em Londres, desenvolveu a ideia de que a Inglaterra usufruía de tudo aquilo que lhe parecesse vantajoso no comércio entre Inglaterra e Portugal. ${ }^{19}$

Em Viena tem nova missão diplomática, durante a qual se casa com a sua segunda esposa, Maria Leonor Ernestina Daun, que mantinha boas relações com a imperatriz e com dona Maria Ana (esposa de Dom João V). Tendo em vista o precário estado de saúde do soberano português, dona Maria Ana assume a regência e logo pede o auxílio de Carvalho e Melo para uma questão de importação de trigo que envolvia a Inglaterra. Isso deixou Pombal mais próximo do centro das decisões, o que veio a se confirmar com a morte de Dom João V, em julho de 1750.

Já D. Luís de Almeida Portugal e Mascarenhas (50 Conde de Avintes e $2^{\circ}$ Marquês do Lavradio) descendia de uma família de nobres, ligados a longa data à corte portuguesa. Nasceu em Ribaldeira, aos 27 dias do mês de julho de 1729. Seguiu a carreira militar, que foi iniciada logo aos 10 anos de idade, quando soldado no regimento de seu pai. Foi educado por um abade francês e aos 20 anos fora conhecer as cortes espanhola e francesa a fim de completar a sua educação. Naquelas nações convive com grandes nomes da arte da guerra. Em 1761 é nomeado coronel comandante do regimento de Cascais. Nesse mesmo ano teve um papel ativo no conflito com os ingleses. Seu prestígio na corte evidenciou-se quando D. José pensou em empregá-lo como aio na educação de seu neto, porém Pombal tinha outros planos para Lavradio, pois "achava-se a Capitania da Bahia em grande desordem, não achando ninguém tão capaz para remediar esse mal como o Marquês do Lavradio".20

A ideia de partir para a Bahia não soava mal a Lavradio, pois era sobrinho do último Duque de Aveiro, parente próximo dos Tavoras (acusados pelo atentado a D. José). Em 1767, é nomeado governador e capitão general da

18 Sobre o Marquês de Pombal destaca-se: FALCON, Francisco. (1982) A época pombalina: política econômica e monarquia ilustrada. São Paulo, Ática, 1982; O império luso-brasileiro e a questão da dependência inglesa - um estudo de caso: a política mercantilista durante a Época Pombalina, e a sombra do Tratado de Methuen. Nova Economia, Belo Horizonte, vol.15, n.2 (2005), p. 11-34; AZEVEDO, João Lúcio de. O Marquês de Pombal e sua época. São Paulo: Alameda, 2004; MAXWELL, Kenneth. O paradoxo do I/uminismo. São Paulo: Cia das Letras, 1996; Pombal and the nationalization of the Luso-Brazilian Economy. Hispanic American Historical Review, vol. XLVIII, n. 4 (1968), p. 608-631.

${ }^{19}$ FALCON, $\mathrm{O}$ império luso-brasileiro...

20 D'ALMEIDA, D. José. Vice-Reinado de D. Luiz D'Almeida Portugal. São Paulo: Cia Editora Nacional, 1942, p.5. 
Bahia, embarcando de Lisboa para essa Capitania em fevereiro de 1768, chegando 53 dias depois. Se por um lado estava afastado do centro do poder, por outro sabia que seus poderes eram vastíssimos em solo colonial.

Seu governo na Bahia tratou de reestruturar as finanças daquela importante Capitania. O reflexo de sua administração foi a nomeação para ViceRei do mais importante domínio português, o Rio de Janeiro, capital desde 1763. Suas cartas revelam que não ambicionava o governo e gostaria de regressar a fim de cuidar de sua numerosa família, porém respeitava o real desígnio.

Na segunda metade do século XVIII, o espaço fluminense transformouse no principal locus da dinâmica econômica colonial brasileira. Com a intensificação do fluxo de pessoas, navios e comércio, natural que também ocorresse uma ampliação da importância política do Rio dentro do Império Ultramarino Português. Isso se evidencia em 1763, quando é transferida a capital de Salvador para o Rio de Janeiro. Outro exemplo é o Tribunal da Relação do Rio de Janeiro, criado já em 1750 para resolver pendências jurídicas ocorridas no sul, centro-oeste e sudeste do país. Como consequência, houve a migração de juristas, da alta nobreza e da burocracia portuguesa, além de um maior contingente de militares. Esse movimento foi acentuado com o Tratado de Madri de 1750, o qual fez com que passassem pelo Rio de Janeiro matemáticos, geógrafos e engenheiros. Acrescenta-se a presença de estrangeiros que também influenciavam o grupo de intelectuais, cientistas e artistas que habitavam a cidade. Esse deslocamento, anos mais tarde (1772), colaborou na formação de uma Academia Científica na capital do Brasil. O ouro acabou por consolidar a posição geográfica privilegiada do Rio de Janeiro, sendo esse o principal porto de ligação entre as Minas e o Reino.

Embora a economia do Rio de Janeiro prosperasse, Lavradio encontra um cenário pouco animador ao desembarcar no Paço em 1770. Dívidas, fortificações mal construídas, armazéns desprovidos e falta de recursos. De início, estabeleceu fábricas de ferraria, serralharia e carpintaria, a fim de realizar os ajustes necessários na defesa da cidade, aumentando o efetivo de soldados e estabelecendo novas diretrizes no treinamento da tropa (como a proibição dos castigos fortes e exercícios em estações quentes).

As finanças da Capitania, segundo Lavradio, também não iam bem, decorrente da prática de contrabando e do descaso na arrecadação dos navios que arribavam na alfândega do Rio de Janeiro. Como a principal fonte de arrecadação da Fazenda Real era a dízima da alfândega, um maior controle sobre a entrada e saída de navios assim como das mercadorias desembarcadas se fazia, mais do que necessário, mais eficiente. Lavradio empenhou-se em elevar o controle da movimentação portuária e ajustar os direitos sobre produtos que pouco ou muito pagavam. $\mathrm{O}$ vice-rei tratou de elevar as receitas adotando uma série de medidas. Em especial, incentivou a implementação de novas culturas (arroz, anil, cochonilha, linho cânhamo e etc), combateu o contrabando (especialmente com os ingleses), reajustou as despesas, construiu uma nova alfândega, quitou em espécie aos que deviam à Fazenda Real, entre outras medidas. Isso deveria ser posto em prática, pois 
além de achar grandes despesas e diminutas receitas, a Fazenda Real devia as 3 praças do Rio de Janeiro, Colônia e Santa Catarina mais de 3 milhões de cruzados, dívida que tinha causado grandes prejuízos ao comércio, fazendo quebrar um grande número de casas de comércio (...). ${ }^{21}$

O empenho do Marquês do Lavradio em recuperar as finanças da Capitania do Rio de Janeiro se mostrou positivo tendo em vista a elevação da arrecadação da dízima da alfândega do Rio de Janeiro pós 1770. Contudo, devido aos conflitos com os castelhanos no sul, ocorre a queda da arrecadação pós 1772. Observe-se o gráfico 1:

\section{Gráfico 1 - Arrecadação da dízima da alfândega do Rio de Janeiro: 1769-79}

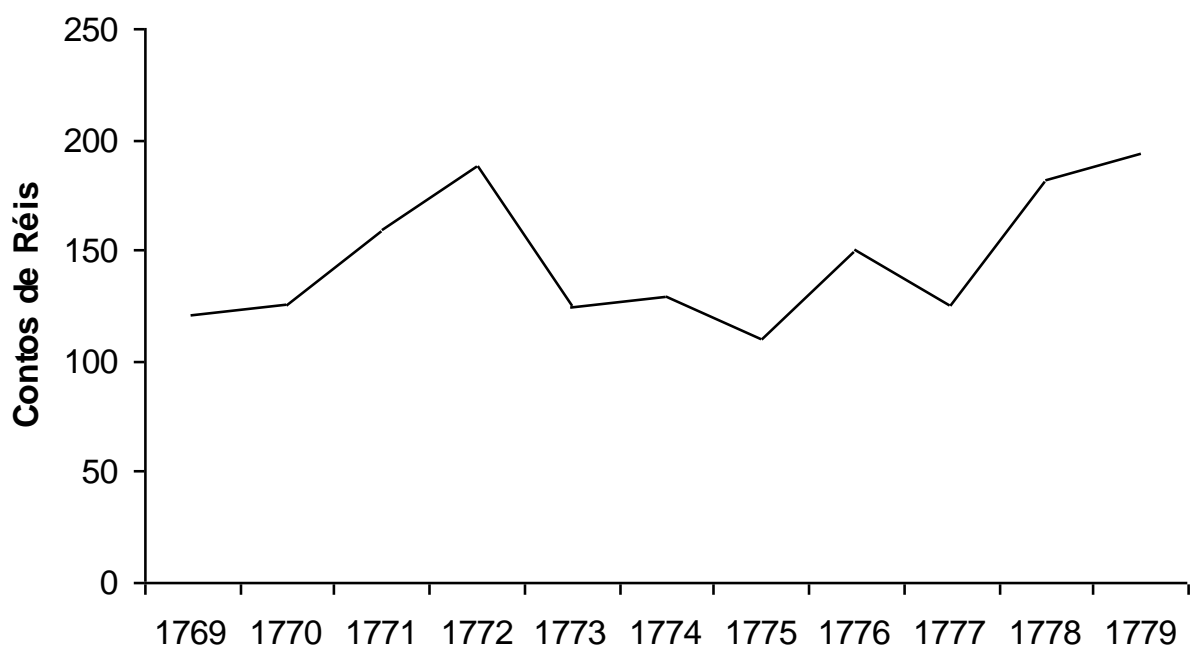

Fonte: Arquivo Nacional do Tribunal de Contas (ANTC), livro 4057.

Entretanto, o principal meio para se desvencilhar da diminuta receita era a arrematação de contratos reais por homens de negócios de grossos cabedais e não mais "mascates e traficantes", os quais deixavam de realizar, na maior parte das vezes, o preço contratado. Além disso, existia uma maior segurança no pagamento dos quartéis de cada contrato, uma vez que o arrematador era um negociante que possuía giro, fiadores e demais garantias de pagamento para o governo.

Esse período presenciou a implementação de novas culturas no Rio de Janeiro. Na verdade, essas medidas de fomento estão inseridas num contexto peculiar. De um lado, existe o crescimento da demanda inglesa por matérias-

\footnotetext{
${ }^{21}$ D'ALMEIDA, op. cit., p.32.
} 
primas, fruto da Revolução Industrial. De outro, as medidas pombalinas de fomento agrícola a fim de suprir a incipiente indústria portuguesa.

A produção no Rio de Janeiro, na primeira metade do setecentos, estava concentrada no açúcar e na mandioca. ${ }^{22}$ Esse cenário foi alterado a partir de 1750, com o incentivo da Coroa para que se diversificasse a pauta de exportação fluminense e brasileira. Nesse sentido, várias foram as tentativas de se introduzir novas culturas no Rio. Dentre essas, destaca-se o linho cânhamo, a amoreira (para se criar o bicho-da-seda), a cochonilha, o anil, o tabaco, o café e o arroz.

Importante perceber que os agentes envolvidos nessas atividades são contratadores. Portanto, além de arrematadores, exercem outras atividades a fim de consolidar a sua posição na praça carioca. A diversificação de seus negócios parecia ser uma estratégia empregada pelos negociantes com 0 objetivo de obter giro e elevar a sua renda. O período de maior apoio da Coroa para a diversificação agrícola fluminense deu-se durante a administração do Marquês de Lavradio (1769-79) ${ }^{23}$ e de Luís de Vasconcelos (1779-90).

\section{Contratadores e contratos no Atlântico Sul}

O processo de intensificação do comércio, aumentando uma interligação com as diferentes partes do Brasil, especialmente entre Rio de Janeiro e Lisboa, engendrou a formação de um grupo social (homens de negócio) ligado ao comércio intra e extracolônia. Gradualmente, os homens de grosso trato superam o grupo de pressão de grandes fazendeiros (ligados ao setor rural, também designados por nobreza da terra) ${ }^{24}$ em face da expansão das rotas de comércio geradas com a descoberta do ouro mineiro o que põe à mostra uma nova estrutura na condução da lide política.

Agora, os homens de grosso trato tomam a frente nesse processo e abarcam boa parte dos negócios decorrentes desse incremento no tráfico comercial. Isso também pode ser verificado na arrematação dos principais contratos que envolviam a praça carioca, a região sul e mineira. Os negociantes cariocas (como Anacleto Elias da Fonseca) destacam-se como alguns dos principais arrematadores, tanto em quantidade de contratos arrematados quanto nos seus valores. Abaixo, os principais contratos envolvendo a economia do Atlântico sul entre 1750 a 1780.

\footnotetext{
${ }^{22}$ LOBO, Eulália Maria L. Rio de Janeiro e Charleston, S. C.: as comunidades de mercadores no século XVIII. Journal of Inter-American Studies and World Affairs, Vol.12, n.4 (1970), p.25-45.

${ }^{23}$ Sobre a administração do Marquês do Lavradio, ver ALDEN, D. Royal Government in colonial Brazil: with special reference to the administration of the Marquis of Lavradio, Viceroy, 17691779. Berkeley: University of California Press, 1968; D'ALMEIDA, op.cit.

${ }^{24}$ FRAGOSO, João Luís. A Espera das frotas: micro-história tapuia e a nobreza principal da terra (Rio de Janeiro, C.1600 - c.1750). Concurso Público para Professor Titular de Teoria da História do Departamento de História da Universidade Federal do Rio de Janeiro). Rio de Janeiro: PPHIS-UFRJ, 2005.
} 
Quadro 1 - Principais contratos envolvendo a economia do Atlântico Sul: 1750-1780

\begin{tabular}{|c|c|c|c|c|}
\hline Contrato & 1750 & 1760 & 1770 & 1780 \\
\hline $\begin{array}{l}\text { Direitos da saída dos escravos } \\
\text { para as MG }\end{array}$ & 105.785 .000 & 38.252 .000 & 48.425 .000 & N.I. \\
\hline Dízimo da chancelaria do RJ & N.I. & 4.424 .000 & 4.010 .000 & N.I. \\
\hline Dízimo real da capitania do RJ & 74.040 .000 & 84.355 .000 & 86.400 .000 & 86.400 .000 \\
\hline $\begin{array}{l}\text { Entradas do caminho novo e } \\
\text { velho }\end{array}$ & 732.000 .000 & 734.400 .000 & 944.000 .000 & N.I. \\
\hline Estanco do tabaco & 55.000 .000 & N.I. & $\mathrm{N}$ & N.I. \\
\hline Estanco do sal do Brasil ( 6 anos) & 293.400 .000 & 246.030 .000 & 254.415 .000 & 273.600 .000 \\
\hline Nau guarda costa & 16.100 .000 & N.I. & $\mathrm{N}$ & N.I. \\
\hline $\begin{array}{l}\text { Passagens dos rios Paraíba e } \\
\text { Paraibuna }\end{array}$ & 40.400 .000 & 48.045 .000 & 35.250 .000 & N.I. \\
\hline Passagens do rio São João & N.I. & 286.667 & 300.000 & N.I. \\
\hline $\begin{array}{l}\text { Pesca da baleia das costa do } \\
\text { Brasil (12 anos) }\end{array}$ & 231.600 .000 & 384.000 .000 & 480.000 .000 & 576.000 .000 \\
\hline Subsídio do azeite doce & 9.793 .333 & 8.460 .000 & 8.700 .000 & N.I. \\
\hline $\begin{array}{l}\text { Subsídio da aguardente do Reino } \\
\text { e Ilhas }\end{array}$ & 15.466 .667 & 15.830 .000 & 14.130 .000 & N.I. \\
\hline $\begin{array}{l}\text { Subsídio da aguardente da terra } \\
\text { (geribitas) }\end{array}$ & 18.600 .000 & N.I. & 14.150 .000 & N.I. \\
\hline Subsídio grande dos vinhos & N.I. & 17.068 .333 & N. & N.I. \\
\hline Subsídio pequeno dos vinhos & 11.900 .000 & 13.273 .333 & N.I. & N.I. \\
\hline
\end{tabular}

Fonte: Pesavento (2009), prelo. * Local onde foi arrematado o contrato.

Impossível agrupar um conjunto de informações sobre todos os contratadores. Contudo, apresenta-se uma tentativa de estruturar a trajetória de alguns desses. Dentre os contratadores, no período da amostra, aqueles que arrematam um maior número de contratos destacam-se: 
Quadro 2 - Principais contratadores (quatro ou mais contratos arrendados): 1760-1770

\begin{tabular}{|l|l|l|l|l|}
\hline Negociantes & $\begin{array}{l}\mathbf{N}^{0} \text { de } \\
\text { Sócios* }\end{array}$ & $\begin{array}{l}\mathbf{N}^{0} \text { de } \\
\text { contratos }\end{array}$ & $\begin{array}{l}\text { Total } \\
\text { (Contos de Réis) }\end{array}$ & Local** \\
\hline Ignácio Pedro Quintela & 4 & 6 & 1.655 & LX \\
\hline Bernardo Gomes Costa & $\mathbf{6}$ & $\mathbf{1 5}$ & $\mathbf{9 5 2}$ & RJ \\
\hline André Pereira de Meireles & 10 & 7 & 661 & RJ \\
\hline Anacleto Elias da & & $\mathbf{1 2}$ & $\mathbf{4 7 2}$ & RJ \\
\hline Fonseca & $\mathbf{6}$ & 4 & 418 & LX \\
\hline José Alvares de Mira & 3 & 397 & LX \\
\hline Domingos Dias da Silva & 3 & 4 & 397 & RJ \\
\hline Simão Gomes Silva & 6 & 6 & 281 & RJ \\
\hline Antonio Lopes da Costa & $\mathbf{1 0}$ & $\mathbf{6}$ & $\mathbf{2 7 7}$ & LX \\
\hline Francisco da Silva Pereira & N.I. & 6 & 223 & \\
\hline João Antunes de Araújo & & & & RJ \\
\hline Lima & 5 & 5 & 194 & RJ \\
\hline Lourenço Ferreira Ribeiro & 5 & 4 & 108 & RJ \\
\hline Miguel de Alvarenga Braga & 5 & 4 & 108 & RJ \\
\hline Francisco Ferreira Rocha & 5 & 4 & 108 & RJ \\
\hline Lourenço Fernandes Viana & 11 & 4 & 104 & RJ \\
\hline José Caetano Alvares & 11 & 5 & 104 & \\
\hline Antonio Pinto de & & & & RJ \\
\hline Miranda & $\mathbf{1 1}$ & $\mathbf{4}$ & $\mathbf{1 0 4}$ & RJ \\
\hline Manoel da Costa Cardoso & 11 & 4 & 104 & \\
\hline Francisco Pinheiro & & & & RJ \\
\hline Guimarães & 11 & 4 & 104 & RJ \\
\hline Francisco José dos Santos & 11 & 4 & 104 & RJ \\
\hline Francisco Lopes de Sousa & 11 & 5 & 104 & RJ \\
\hline Antonio Leite Pereira & 11 & 4 & 104 & RJ \\
\hline Agostinho de Faria Monteiro & 11 & 4 & 104 & 104 \\
\hline Pedro Correa Lima & 11 & 4 & & \\
\hline & & & & \\
\hline
\end{tabular}

Fonte: Pesavento (2009), no prelo. * média por contrato. ${ }^{* *}$ local de atuação mercantil do contratante.

Apesar de não se ter acesso a informações de todos os personagens envolvidos, alguns foram destacados para análise de suas trajetórias mercantis. Dentre os contratadores, dos quais se obteve documentos, destacam-se os seguintes: Anacleto Elias da Fonseca, Antônio Lopes da Costa e Antônio Pinto de Miranda (em negrito no quadro 2). 
Esses negociantes eram sócios entre si, na maioria dos contratos arrematados na praça carioca. Todos realizaram agências para grandes contratadores ou administraram contratos antes de os arrematarem, o que engendrou expertise e "canais" importantes não só para seus negócios mas também para suas futuras arrematações.

Percebe-se pelo quadro 2 que os principais arrematadores eram moradores da praça carioca (local). Ao contrário do que ocorria desde o século XVII, os contratadores não pertenciam à nobreza da terra, mas eram reinóis ou moradores do Rio de Janeiro. Contudo, quando se observam as procurações e escrituras públicas de compra e venda ${ }^{25}$ desses, percebe-se que a atuação deles não estava restrita ao Rio de Janeiro, mas sim em diversas partes do ultramar. Além disso, diversificavam seus negócios em diferentes segmentos de investimento como empréstimos, produção agrícola, compra e venda de bens, entre outros. Um dos principais personagens da cena político-econômica fluminense durante fins do século XVIII e início do século XIX foi Anacleto Elias da Fonseca ${ }^{26}$. Anacleto nasceu em Lisboa, em 1719, filho de Bernardo da Fonseca (mercador que foi a Lisboa) e de Bernarda Maria do Espírito Santo. Em 1742, data de seu aceite como Familiar, Anacleto era comissário de fazendas para o Rio de Janeiro em Lisboa, solteiro e morador em Lisboa. Seu tio Caetano da Costa Fonseca (o qual aparece em duas doações para casamento de seus sobrinhos, feita em 1750) vivia de seu negócio e já era habilitado pelo tribunal do Santo Ofício. Entre os depoimentos constantes no processo de Anacleto, percebe-se que a maioria é constituída por HNLX, como Manoel Gonçalves Leque e seu irmão Antônio da Silva Leque, este que aparece em sociedade com Jose da Silva Leque envolvendo negócios em Colônia do Sacramento. Parece ser dessa sociedade a relação que Anacleto vai construir em Colônia. Além dos negociantes citados, também aparece Antonio Luis (tio por afinidade do habilitando).

Segundo consta no processo de Anacleto, esse realizava seus negócios com o Brasil, via Lisboa, em sociedade de seu pai. Nesse período, existiam atividades que não se restringiam ao círculo Lisboa e Rio de Janeiro. Após três anos, Anacleto casa com D. Joana Maria de Seixas, natural da cidade do Rio de Janeiro. Joana é filha legítima de André de Barros Brandrão e de D. Luiza de Seixas, moradores no Rio e membros da "nobreza da terra"27. Joana tem duas irmãs, D. Francisca Maria Xavier de Seixas, casada com Manoel de Araújo Lima, e outra chamada D. Thereza Maria de Barros, casada com João Teixeira da Silva, ambos Familiares do Santo Ofício. "As filhas de André de Barros Brandão e de dona Luiza de Seixas; esta bisneta do senhor de engenho Sebastião Coelho Amim e que tinha por antepassado o conquistador Pedro Espinha". ${ }^{28}$ No mesmo processo Anacleto aparece como assistente no Rio.

\footnotetext{
25 Ver Pesavento, 2009, no prelo.

26 Informações contidas em Pesavento, 2009, no prelo. Processo de Anacleto como familiar: ANTT, habilitações do Santo Ofício, maço 10, n.155 (Inquisição de Lisboa).

${ }^{27}$ FRAGOSO, op. cit.

${ }^{28}$ Ibidem, p.228.
} 
Anacleto estava inserido numa rede em Lisboa que lhe permitiu acesso à lide mercantil e, no Rio, ao se casar com Joana, ingressou numa outra rede, a política! Tanto que em 1759 já aparece como cavaleiro da Ordem de Cristo. Depois disso, em 1770, arremata o seu primeiro contrato (dízimo reais) junto com Antônio Lopes da Costa, Bernardo Gomes Costa, Simão Gomes Silva, André Pereira de Meireles, Luís Pereira de Sousa e Manoel Barbosa dos Santos.

Mas antes de sua participação na arrematação de contratos, Anacleto percorreu uma trajetória comercial intensa. O primeiro negócio de Anacleto já atuando na praça carioca (a que se teve acesso) é uma sociedade mercantil com o capitão José da Costa Pereira (Ordem de Cristo) no ano de 1751. Naquela oportunidade, José era morador do Rio de Janeiro e estava de partida para Lisboa. A sociedade, de comércio entre Lisboa e a praça carioca, era por quatro anos sendo que cada um dos sócios entrou com 20.000 cruzados de capital inicial (AN, $1^{0}$ oficio de notas, livro121). José remetia fazendas para 0 Rio e Anacleto as vendia. Esse tipo de comércio Anacleto realizava em Lisboa antes de vir ao Brasil.

Fragoso aponta que os negócios de Anacleto, durante os anos de 1753 e 1754, iam além do fluxo de bens entre as praças carioca e lisboeta, uma vez que comercializava tecidos da Índia, e com a região do Prata, desde antes de $1757 .{ }^{29}$ Segundo consta em seu processo de habilitação na Ordem de Cristo, "já em data anterior a 1757 tinha negócios na Colônia de Sacramento [e] que logo que fora para o Rio tivera o exercício de caixeiro em uma loja de mercador e depois entrara a ser homem de negócio (...) fazendo suas carregações para a Colônia e Angola e outros mais portos, tendo interesses em navios". ${ }^{30}$

Não é por acaso que, por volta de 1759, Anacleto Elias da Fonseca aparece como cavaleiro da Ordem de Cristo tendo como testemunha o grande negociante Domingos Ferreira da Veiga. ${ }^{31}$ Durante a década de 1760 , Anacleto é outorgante de diversos homens de negócio no Rio de Janeiro.

Passada a etapa de caixeiro e já articulado com os negócios do império ultramarino, Anacleto está pronto para expandir seus negócios. Em 1770, arremata seu primeiro contrato (dízimos reais da Capitania do Rio de Janeiro) por três anos no valor de 86:400\$000 réis. Anacleto tinha como sócios naquele contrato os homens de negócios da praça carioca, Antônio Lopes da Costa, Bernardo Gomes Costa, Simão Gomes Silva, André Pereira de Meireles, Luis Pereira de Sousa e Manoel Barbosa dos Santos.

Nessa nova etapa, Anacleto adentra numa seara restrita a poucos e importantes negociantes: a arrematação de contratos régios. Cabe lembrar que Domingos Ferreira da Veiga foi testemunha de Anacleto quando da obtenção da Ordem de Cristo (Domingos foi um dos grandes contratadores atuantes em Lisboa). Em março de 1772, Anacleto recebe o posto de capitão da Companhia de Ordenança da freguesia de Nossa Senhora da Candelária da cidade do Rio de Janeiro.

${ }^{29}$ OSÓRIO, Helen. Comerciantes do Rio Grande de São Pedro: formação, recrutamento e negócios de um grupo mercantil da América portuguesa. Revista Brasileira de História, São Paulo, v. 20, n.39 (2000), p. 115-134.

${ }^{30}$ Idem.

${ }^{31}$ Idem. 
Antônio Lopes da Costa ${ }^{32}$ foi porteiro e guarda da Alfândega do Rio de Janeiro e capitão de navio, realizando diversas viagens entre o Rio de Janeiro e Lisboa (ou seus navios), o que reforçava ainda mais o leque informacional de Antonio Lopes, facilitando a realização de novas transações econômicas. Além disso, aparece como procurador de vários homens de negócio lisboetas, britânicos, franceses e alemães. A cobrança dos fretes de seus navios saídos do Rio para Lisboa era realizada por Domingos Gomes da Costa ou José Ferreira da Veiga, dois grandes contratadores (por exemplo, do estanco do sal no Brasil em 1758). Antonio não se limitava aos negócios ultramarinos, pois foi sócio de uma fábrica de arroz no Rio de Janeiro. ${ }^{33}$ Por último, participava de negócios com o Oriente através do comércio de tecidos na İ́ndia. ${ }^{34}$

Antônio Lopes da Costa foi cavaleiro da Ordem de Cristo, por volta de 1747. Por ser "capitão de navio", realizou diversas viagens entre o Rio de Janeiro e Lisboa (ou seus navios), o que reforçava ainda mais o seu leque informacional, facilitando a realização de novas transações econômicas. Sargento-mor, por volta de 1770, morre em 1773. Antônio Pinto de Miranda é natural do Porto, onde nasceu em $1714 .{ }^{35}$ Casou-se com Maria Pinto (também natural do Porto, moradora do Rio). Por volta de 1740, vai ao Rio ainda "rapaz". A Santa Casa da Misericórdia do Rio de Janeiro empresta-lhe 6 contos de réis, em 1752.

Familiar do Santo Ofício em 1760, com cabedal de mais 30.000 cruzados, administrou nesse mesmo ano o contrato das Geribitas para Francisco José da Fonseca (homem de negócios de Lisboa). Em 1761 tinha sociedade com Balthazar Pinto de Miranda e em 1763 é nomeado capitão dos moedeiros do Rio de Janeiro, por 2 anos, depois administrar o dízimo da alfândega do Rio. Em 1769 forma uma sociedade para uma fábrica de linho de cânhamo com Manoel Luis Vieira, Domingos Lopes Loureiro, Antônio de Oliveira Durão e Francisco Pinheiro Guimarães (também sócio nos seus contratos). Foi outorgante de vários homens de negócios lisboetas - entre eles Ignácio Pedro Quintela (outro grande contratador, como da pesca da baleia e do estanco de sal) -, italianos, hamburgueses e franceses.

Pode-se afirmar que Antônio Pinto de Miranda e Antônio Lopes da Costa são negociantes que encerraram suas atuações mercantis na praça carioca em fins do século XVIII. Já Anacleto verá seus negócios se prolongarem durante o fim do século XVIII e o início do século XIX (como a arrematação do contrato do dízimo real do Rio, em 1790, por 86 contos de réis junto com Brás Carneiro Leão). Outro aspecto importante é o fato de que as arrematações de contratos, além de serem um investimento de rentabilidade de curto prazo, reforçavam o seu prestígio com a sociedade local e com a Coroa, robustecendo suas redes de atuação, o que permitia a ampliação de seus negócios.

32 PESAVENTO, op.cit., 2009.

33 PESAVENTO, Fábio. $O$ azul fluminense: o anil no Rio de Janeiro colonial, 1749-1818. Dissertação de Mestrado. Niterói: PPGE-UFF, 2005.

${ }^{34}$ ANTUNES, op. cit.

35 ANTT, Habilitações do Santo Ofício - maço 136, doc. 2257 (Inquisição de Lisboa). 
Pode-se notar que os contratadores pertencem a uma elite na qual desempenham um papel importante na condução de negócios na economia colonial fluminense, não só por meio da arrematação de contratos, mas também pela diversificação de seus investimentos. 